\title{
Barrier to Rotation about Sulfur-Sulfur Bonds in Homocyclic Sulfur Molecules [1]
}

\author{
Ralf Steudel \\ Institut für Anorganische und Analytische Chemie, Technische Universität Berlin, \\ Sekr. C 2, D-1000 Berlin 12
}

Z. Naturforsch. 38b, 543-545 (1983); received January 18, 1983

Elemental Sulfur, Sulfur Rings, Sulfur-Sulfur Bonds, Torsional Barrier, Bond Distances

It is shown that the distances (d) of the 19 longest bonds in 9 homocyclic sulfur rings of type $S_{n}(n=6-20)$ depend on the torsional angles $(\tau)$ which vary between $0^{\circ}$ and $140^{\circ}$. The function $\mathrm{d}=\mathrm{f}(\tau)$ is smallest for $\tau=90-100^{\circ}$ and largest for $\tau=0^{\circ}$; the corresponding bond distance variation amounts to $13 \mathrm{pm}$ or $6 \%$. The height of the torsional cis-barrier is estimated from the enthalpy of formation of gaseous $S_{7}$ as equal to or smaller than $24 \mathrm{~kJ} / \mathrm{mol}$.

The rotational barrier in $\mathrm{H}_{2} \mathrm{~S}_{2}$ and its organic derivatives, $\mathrm{R}_{2} \mathrm{~S}_{2}$, is well established and has been studied by various experimental techniques as well as by molecular orbital calculations [2,3]. Due to the lone pair - lone pair interaction of the two sulfur atoms a torsional angle $\left(\tau_{\mathrm{ss}}\right)$ of approximately $90^{\circ}$ is most favorable energetically while angles of both $0^{\circ}$ and $180^{\circ}$ correspond to energy maxima and, therefore, rotational barriers. Most authors agree that the cis-barrier $\left(\tau=0^{\circ}\right)$ is higher than the trans-barrier $\left(\tau=180^{\circ}\right)$ but there is no agreement on the barrier heights. $\mathrm{MO}$ calculations on $\mathrm{H}_{2} \mathrm{~S}_{2}$ and $\left(\mathrm{CH}_{3}\right)_{2} \mathrm{~S}_{2}$ have resulted in cis-barriers of between 3 and $192 \mathrm{~kJ} / \mathrm{mol}$ and trans-barriers of between 6 and $61 \mathrm{~kJ} / \mathrm{mol}$ [3]. For longer sulfur chains as in $\mathrm{H}_{2} \mathrm{~S}_{n}$ or $\mathrm{R}_{2} \mathrm{~S}_{n}(n>2)$ no such calculations have been published.

The most reliable information about the actual barrier height comes from the NMR spectroscopic observation of the rotation about the SS bond in certain acyclic organic disulfides, R-S-S-R'. In the absence of steric effects the magnitude of the barrier was found to be $28 \mathrm{~kJ} / \mathrm{mol}$ [4].

Deviations from the most favorable torsional angle of $90^{\circ}$ result in weak SS bonds as can be seen from the dependence of both the bond distance [5] and the wavenumber of the SS stretching vibration [6] on $\tau_{\mathrm{SS}}$. Disulfides with $\tau_{\mathrm{SS}}$ ranging from $0^{\circ}$ to $180^{\circ}$ are known, and the SS bond length varies accordingly between 200 and $211 \mathrm{pm}[5,7]$.

However, extensive studies on numerous compounds have shown that in addition to the torsional angle the inductive effect of certain substituents

$0340-5087 / 83 / 0500-0543 / \$ 01.00 / 0$ as well as the overall conformation of the molecule influence the SS bond strength $[4,8]$. In homocyclic sulfur molecules of type $S_{n}$ no such problems are to be expected. So far 15 crystalline sulfur allotropes consisting of ring molecules have been studied by $\mathrm{X}$-ray diffraction and torsional angles of between $0^{\circ}$ and $140^{\circ}$ have been observed (Table I). These data allow to correlate $\tau_{\mathrm{SS}}$ with the corresponding bond distance, $d_{\mathrm{ss}}$, as shown in Fig. 1 . It can be seen that the most favorable $\tau$ values are those near $90^{\circ}$ while both larger and smaller torsional angles result in longer and therefore weaker bonds.

In previous publications we have shown that a weak SS bond in a homoatomic chain or ring, caused

Table I. Smallest and largest torsional angles $\left(\tau_{\mathrm{Ss}}\right)$ and related bond distances $\left(\mathrm{d}_{\mathrm{SS}}\right)$ in sulfur allotropes consisting of cyclic molecules.

\begin{tabular}{lrll}
\hline Compound & $\tau_{\mathrm{SS}}\left({ }^{\circ}\right)$ & $\mathrm{d}_{\mathrm{SS}}(\mathrm{pm})$ & Ref. \\
\hline$\delta-\mathrm{S}_{7}$ & 0.3 & 218.2 & $9 \mathrm{a}$ \\
$\gamma-\mathrm{S}_{7}$ & 0.4 & 217.5 & $9 \mathrm{a}$ \\
$\delta-\mathrm{S}_{7}$ & 2.4 & 218.0 & $9 \mathrm{a}$ \\
$\mathrm{S}_{13}$ & 29.5 & 211.3 & $9 \mathrm{~b}$ \\
$\mathrm{~S}_{20}$ & 66.3 & 210.4 & $9 \mathrm{c}$ \\
$\beta-\mathrm{S}_{18}$ & 66.5 & 209.7 & $9 \mathrm{~d}$ \\
$\mathrm{~S}_{6}$ & 73.8 & 206.8 & $9 \mathrm{e}$ \\
$\mathrm{S}_{12}$ & 86.0 & 205.2 & $9 \mathrm{f}$ \\
$\mathrm{S}_{12}$ & 88.6 & 204.8 & $9 \mathrm{f}$ \\
$\mathrm{S}_{12}$ & 89.4 & 205.7 & $9 \mathrm{f}$ \\
$\mathrm{S}_{12} \cdot \mathrm{CS}_{2}$ & 87.2 & 205.4 & $9 \mathrm{f}$ \\
$\mathrm{S}_{8}$ & 98.5 & 205.1 & $9 \mathrm{~g}$ \\
$\mathrm{~S}_{13}$ & 111.2 & 207.3 & $9 \mathrm{~b}$ \\
$\mathrm{~S}_{13}$ & 113.1 & 207.3 & $9 \mathrm{~b}$ \\
$\mathrm{~S}_{13}$ & 114.1 & 207.3 & $9 \mathrm{~b}$ \\
$\mathrm{~S}_{13}$ & 116.3 & 206.9 & $9 \mathrm{~b}$ \\
$\mathrm{~S}_{10}$ & 121.5 & 207.8 & $9 \mathrm{~h}$ \\
$\mathrm{~S}_{10}$ & 123.7 & 207.1 & $9 \mathrm{~h}$ \\
$\mathrm{~S}_{11}$ & 140 & 211.0 & $9 \mathrm{i}$ \\
\hline
\end{tabular}


by either torsional strain or the impact of substituents, results in a reinforcement of the two neighboring bonds whose bond distances therefore decrease resulting in the well known alternation of bond distances observed in many polysulfur compounds [2]. The length of a particular bond in a molecule $S_{n}(n \geqslant 6)$ is therefore not only a function of the torsional angle but is influenced also by the strength of the neighboring bonds. To avoid difficulties from this effect only those bonds have been listed in Table I and are shown in Fig. 1 which exhibit the smallest or largest torsional angles in the particular ring and whose neighbors show normal torsional angles $\left(75-110^{\circ}\right)$. These bonds will be either the longest or the shortes in the molecule.

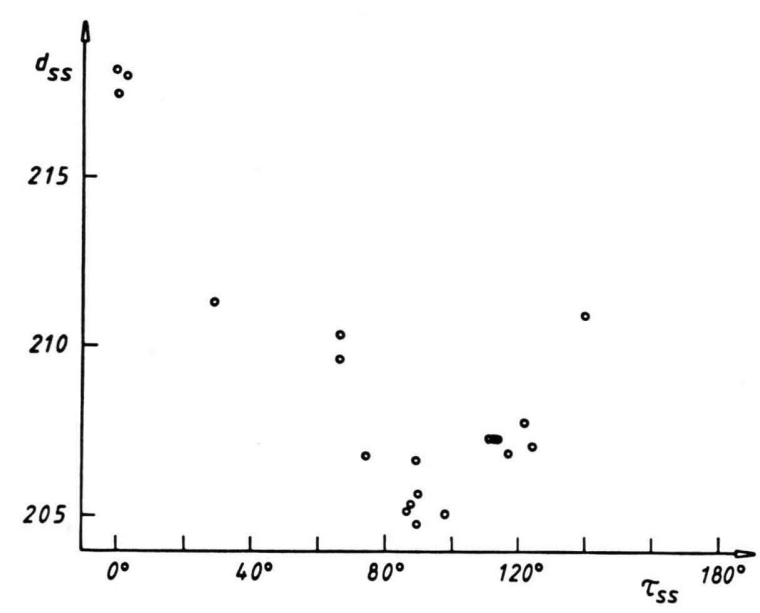

Fig. 1. Dependence of the sulfur-sulfur bond distance $\left(\mathrm{d}_{\mathrm{SS}}\right.$ in $\left.\mathrm{pm}\right)$ in homocyclic sulfur molecules $\mathrm{S}_{n}$ on the torsional angle $\tau_{\mathrm{Ss}}$.

The relationship between $\tau_{\mathrm{SS}}$ and $\mathrm{d}_{\mathrm{SS}}$ shown in Figure 1 is very similar to the corresponding relationship found for disulfides [5]. The three values with $\tau_{\mathrm{SS}}$ near $0^{\circ}$ were taken from the two allotropes of cyclo-heptasulfur $\left(\mathrm{S}_{7}\right)$ the molecules of which are of $\mathrm{C}_{\mathrm{S}}$ symmetry and can be derived formally from $\mathrm{S}_{8}$ by removal of one atom and connection of the chain ends by a particularly long bond. It is this bond which exhibits the unusual torsional angle of $0^{\circ}$, while the other six torsional angles are found in the region $75-109^{\circ}$. The average length of the six related bonds amounts to $205 \mathrm{pm}$, the value observed for $\mathrm{S}_{8}$ and $\mathrm{S}_{12}$ with $\tau=90-100^{\circ}$ (see Table I). The torsional strain of the $S_{7}$ molecule can therefore in a first approximation be regarded as re- stricted to the unique bond, and under these circumstances the height of the torsional barrier can be estimated from the enthalpy of formation of the $\mathrm{S}_{7}$ molecule from $\mathrm{S}_{8}$. In the vapor phase $\Delta \mathrm{H}^{\circ}{ }_{300}$ of the reaction

$$
7 / 8 \mathrm{~S}_{8} \rightleftharpoons \mathrm{S}_{7}
$$

amounts to $24 \mathrm{~kJ} / \mathrm{mol}$ [10]. When six of the seven bonds of $S_{7}$ are on the average energetically almost equivalent to those of $\mathrm{S}_{8}$, then the observed $\Delta \mathrm{H}^{\circ}$ must be the enthalpy change for the transformation of one SS bond from $\mathrm{d}_{\mathrm{SS}}=205 \mathrm{pm}$ and $\tau=98^{\circ}$ in $\mathrm{S}_{8}$ to $218 \mathrm{pm}$ and $\tau=0^{\circ}$ in $\mathrm{S}_{7}$. In other words, the height of the torsional cis-barrier in homocyclic $\mathbf{S}_{n}$ molecules must be equal to or lower than $24 \mathrm{~kJ} / \mathrm{mol}$. The actual barrier height might be even somewhat smaller since there is evidence for a certain amount of additional strain in the $S_{7}$ molecule as can be seen from the bond angles, two of which amount to $102^{\circ}$, while the most favorable value is in the region $105-108^{\circ}$ as in $S_{8}$ and $S_{12}$ [2]. The actual barrier height therefore might be as low as $20 \mathrm{~kJ} / \mathrm{mol}$ and the trans-barrier will be even lower. It follows that sulfur rings $S_{n}(n \geqslant 7)$ cannot be regarded as rigid molecules at $25{ }^{\circ} \mathrm{C}$ or higher temperatures but must be of considerable conformational flexibility both in solution and in the gaseous state. The torsional pseudorotation of $S_{7}$ in the vapor phase has already been deduced from its entropy [11]. The same low barrier can be assumed for compounds containing longer sulfur chains including polymeric sulfur which is an important equilibrium component of liquid sulfur especially at temperatures above $160{ }^{\circ} \mathrm{C}$.

The barrier height deduced above is lower than that observed for organic disulfides. This is a consequence of the bond-bond interaction effect: part of the energy needed to stretch the central bond in the structural unit -S-S-S-S- from $205 \mathrm{pm}\left(\mathrm{S}_{8}\right)$ to $218 \mathrm{pm}\left(\mathrm{S}_{7}\right)$ is gained by the reinforcement of the two neighboring bonds which contract from $205 \mathrm{pm}$ $\left(\mathrm{S}_{8}\right)$ to $200 \mathrm{pm}\left(\mathrm{S}_{7}\right)$. While in organic disulfides a torsional angle $\tau_{\mathrm{SS}}$ of $0^{\circ}$ results in a bond length $d_{\mathrm{SS}}$ of $211 \mathrm{pm}[5,7]$ (without any significant bond-bond interaction), it creates a considerably longer bond $(218 \mathrm{pm})$ in $\mathrm{S}_{7}$. The larger bond distance results in a weaker lone pair-lone pair interaction with the consequence of a lower torsional barrier.

While the above discussion applies to $\mathrm{S}_{7}$ and larger rings it should be noted that $\mathrm{S}_{6}$ might be a much 
more rigid molecule. Molecular models show that pseudorotation of $\mathrm{S}_{6}$ also requires a considerable deformation of the bond angles and, therefore, the barrier height will be higher than in the case of $S_{7}$.
According to a CNDO/2-MO calculation, the boat form of $S_{6}$ is less stable by $16 \mathrm{~kJ} / \mathrm{mol}$ than the chair form with an interconversion barrier of $90 \mathrm{~kJ} / \mathrm{mol}$ [12].
[1] Sulfur Compounds, Part 82.

[2] Reviews: R. Steudel, Angew. Chem. 87, 683 (1975); Angew. Chem. Int. Ed. Engl. 14, 655 (1975); R. Steudel, Top. Curr. Chem. 102, 149 (1982).

[3] R. Laitinen and T. Pakkanen, Acta Chem. Scand., in print; M. E. Schwartz, J. Chem. Phys. 51, 4182 (1969); I. H. Hillier, V. R. Saunders, and J. F. Wyatt, Trans. Faraday Soc. 66, 2665 (1971); J. Pappas, Chem. Phys. 12, 397 (1976); A. Veillard and J. Demuynck, Chem. Phys. Lett. 4, 476 (1970); D. W. Davies, Chem. Phys. Lett. 28, 520 (1974); J. P. Snyder and L. Carlsen, J. Am. Chem. Soc. 99, 2931 (1977) and references 15-16 cited therein; L. J. Saethre, Acta Chem. Scand. 29 A, 558 (1975); G. Wagner and H. Bock, Chem. Ber. 107, 68 (1974); T. Gillbro, Phosph. Sulfur 4, 133 (1978); F. Fehér and R. Schulze-Rettmer, Z. Anorg. Allg. Chem. 295, 262 (1958).

[4] R. R. Fraser, G. Boussard, J. K. Saunders, J. B. Lambert, and C. E. Mixan, J. Am. Chem. Soc. 93, 3822 (1971).

[5] A. Hordvik, Acta Chem. Scand. 20, 1885 (1966); H. E. Van Wart and H. A. Scheraga, J. Phys. Chem. 80, 1823 (1976).

[6] H. E. Van Wart, H. A. Scheraga, and R. B. Martin, J. Phys. Chem. 80, 1832 (1976) and references cited therein.

[7] C. J. Simmons, M. Lunden, and K. Seff, J. Chem. Soc. Chem. Commun. 1979, 595.

[8] H. E. Van Wart and H. A. Scheraga, J. Phys. Chem. 80, 1812 (1976) ; L. S. Higashi, M. Lunden, and K. Seff, J. Am. Chem. Soc. 100, 8101 (1978).
[9] a) R. Steudel, J. Steidel, J. Pickardt, F. Schuster, and R. Reinhardt, Z. Naturforsch. 35 b, 1378 (1980);

b) R. Steudel and J. Steidel, unpublished results ; c) M. Schmidt, E. Wilhelm, T. Debaerdemaeker, E. Hellner, and A. Kutoglu, Z. Anorg. Allg. Chem. 405, 153 (1974);

d) T. Debaerdemaeker and A. Kutoglu, Cryst. Struct. Commun. 3, 611 (1974);

e) J. Steidel, J. Pickardt, and R. Steudel, Z. Naturforsch. 33 b, 1554 (1978);

f) J. Steidel, R. Steudel, and A. Kutoglu, Z. Anorg. Allg. Chem. 476, 171 (1981);

g) P. Coppens, Y. W. Yang, R. H. Blessing, W. F. Cooper, and F. K. Larsen, J. Am. Chem. Soc. 99, 760 (1977);

h) R. Reinhardt, R. Steudel, and F. Schuster, Angew. Chem. 90, 55 (1978), Angew. Chem. Int. Ed. Engl. 17, 57 (1978);

i) J. Steidel and R. Steudel, J. Chem. Soc. Chem. Commun. 1982, 1312.

[10] D. Detry, J. Drowart, P. Goldfinger, H. Keller, and H. Rickert, Z. Phys. Chem. (Frankfurt) 55, 314 (1967); H. Rau, T. R. N. Kutty, and J. R. F. Guedes de Carvalho, J. Chem. Thermodyn. 5, 833 (1973); J. Berkowitz and J. R. Marquardt, J. Chem. Phys. 39, 275 (1963).

[11] R. Steudel and F. Schuster, J. Mol. Struct. 44, 143 (1978).

[12] Z. S. Herman and K. Weiss, Inorg. Chem. 14, $1592(1975)$. 